\title{
Comprehensive Mental Health Facets And Association With Age, Stress And Coping Amid 'The New Normal' Pandemic: How Do Adolescents Differ From Adults?
}

Shweta Singh ( $\nabla$ shwetabhanu3@gmail.com )

King George's Medical University https://orcid.org/0000-0001-7469-5114

Manjistha Datta

King George Medical University: King George's Medical University

Pawan Gupta

King George Medical University: King George's Medical University

Saakshi Batra

King George Medical University: King George's Medical University

Rakesh Tripathi

King George Medical University: King George's Medical University

Pooja Mahour

King George's Medical University

Amit Arya

King George Medical University: King George's Medical University Adarsh Tripathi

King George Medical University: King George's Medical University

Bandna Gupta

King George's Medical University

Manu Agarwal

King George Medical University: King George's Medical University

Anil Nischal

King George Medical University: King George's Medical University

Vivek Agarwal

King George's Medical University

P.K. Dalal

King George Medical University: King George's Medical University

Research article

Keywords: Mental Health, Substance Use, the New Normal, COVID 19 Pandemic, Adolescents, Young Adults, Middle-Age Adults

Posted Date: August 30th, 2021

DOI: https://doi.org/10.21203/rs.3.rs-789569/v1

License: () (1) This work is licensed under a Creative Commons Attribution 4.0 International License. Read Full License 


\section{Abstract}

Background:

Given varied forms of stressors in the backdrop of the COVID 19 pandemic, adolescents are particularly vulnerable to specific mental health challenges. It pertinent to explore how adolescents differ from adults regarding the comprehensive mental health facets amid the 'new normal, i.e., the duration between the first and second wave of COVID-19 in a developing country like India. The present study aimed to compare the comprehensive mental health facets of adolescents with the adults. Also, it aimed to explore the association of mental health facets with age, perceived stress, coping and impact of pandemic.

Methods:

The study followed a cross-sectional design with 1,027 participants [456 adolescents; 347 young and 224 middle age-adults] recruited from schools and colleges. The Comprehensive DSM-5 Self-Rated Level 1 Cross-Cutting Symptom Measure, Perceived Stress Scale and Brief COPE Scale were used for assessment. The difference between groups was analyzed using the Chi-Square Test of Independence and correlational analysis was done using Spearman Rank Correlation. Multiple regression analyses were performed for the mental health facets along with bootstrapping method.

Results:

$33.77 \%$ of adolescents, $25.65 \%$ of young adults, and $17.41 \%$ of middle-aged adults reported that their symptoms started during the pandemic. Compared to adults, the adolescents reported higher depression, anxiety, suicidal ideations, anger, and somatic complaints. Significantly higher adolescent females (39.9\%) were found to have sleep disturbances compared to their male counterparts (25.5\%). Therefore, it can be observed Adolescents are more clinically vulnerable in most domains. The correlational analysis showed that most mental health domains, except substance use showed moderate-to-low correlations with 'Impact of COVID'. Perceived stress, impact of COVID, self-distraction, self-blaming were significant independent positive predictors for all the mental health domains except substance use. 'Age' was negatively associated with depression anxiety, repetitive thoughts, personality changes, suicidal ideations and memory, and positively associated with 'substance use' at low levels. Maladaptive coping was moderately positively correlated with all the mental health domains.

Conclusion:

It can be observed Adolescents are more clinically vulnerable in most domains. This study provides a comprehensive analysis for assessment and clinical decision-making to combat the mental health problems arising and exacerbating due to the COVID-19 pandemic. The findings will help in planning and implementing an appropriate interventional program, and making policy decisions related to the vulnerable group of adolescents.

\section{Background}

While the world has been struggling with the viral pandemic, there has been a "parallel pandemic" of psychopathologies during COVID-19 pandemic . ${ }^{[1]}$ The COVID-19 pandemic indeed did not alter lives merely momentarily during the 'lockdowns' or 'active outbreak phases' only, everyone has been experiencing a longer-lasting transformation in the 'New Normal' phase. Individuals of all developmental stages are impacted in all spheres life including education, employment, socialization and global health. In addition to the general fear of the virus, these drastic changes have demanded radical adaptation, creating heightened stress levels. The struggle to adapt to the 'new normal' and dealing with the vicissitude of this situation has had significant implications for the mental health.

The impact of pandemic could vary in different countries due to variations in socio-economic-cultural factors. For instance, in India, towards the end of 2020 , when the peak phase of the first wave subsided, people started getting accommodated to the new standard guidelines of the 'New Normal' era. Owing to factors such as work-life imbalance and stress associated with the pandemic, an escalation in the levels of academic disruptions, isolation, depression, anxiety, perceived stress, harmful substance use, self-harm, disturbed sleep cycles and suicidal behavior were increased among adolescents and adults. ${ }^{[2,3]}$

With the entire society coping with the same virus, the experience of stress and its impact on the mental health of adolescents and adults is expected to be different. Literature suggests that while adults perceived the risks of COVID-19 to be higher than younger population, they were less worried. ${ }^{[4]}$ Given the increased academic stress, uncertainty, and change in routine, some researchers observed that school-age children and adolescents experienced significant depression, anxiety, and stress during the outbreak. ${ }^{[5]}$ According to Eden et al., ${ }^{[6]}$ stress and anxiety were also present in adolescents and were negatively related to psychological well-being indicators of positive affect, mental health, and flourishing. A study from Ecuador which concluded the relationship of fear of COVID-19 with depression, mediated by anxiety, also showed that major psychological health problems existed among students in the context of the COVID-19 lockdown. ${ }^{[7]}$

The adolescents' lives have been impacted during this pandemic as online classes and online examinations have not been an adequate substitute for the learning that occurs in regular classes. A recent meta-analysis study suggested that depressive and anxiety symptoms in undergraduate students (32\%) were higher compared to graduate students (32\% versus $25 \%$, and $24 \%$ versus $14 \%$, respectively). During this pandemic as the culture of online classes and online proctored examinations has not been an adequate substitute for the learning that occurs in physical classes. In addition to that, there is an existing fear of losing career opportunities shortly due to the economic crisis. ${ }^{[2]}$ A meta-analysis study suggested that depressive and anxiety symptoms in undergraduate students (32\%) were higher compared to graduate students (32\% versus $25 \%$, and $24 \%$ versus $14 \%$, respectively). This difference could be attributed to the possibility of their more incredible experiences with stressful situations; graduate students may have developed better coping strategies than undergraduates. It was also observed that the prevalence of depressive and anxiety symptoms could increase with time among students pursuing higher education.

Page 2/20 
Moreover, it was indicated that students with poor financial backgrounds, female students, and students living alone showed a higher prevalence of depressive and anxiety symptoms. ${ }^{[8]}$ The pandemic has had severe financial and work's implications for the adult population. With the rise in work-from-home culture, balancing professional and personal lives has also been challenging as individuals are expected to complete an increased amount of work at odd hours. ${ }^{[2]}$ While no significant gender differences in levels of anxiety, stress, and depression have been found in most of the studies, ${ }^{[6,9]}$ others do not accept this observation and show that females tend to be more vulnerable to these disorders. ${ }^{[10,11]}$ Findings regarding education are also inconsistent; for instance, in Australia, distress was higher among less educated people, ${ }^{[12]}$ whereas stress was higher among more educated participants in China. ${ }^{[13]}$

\section{Present study}

Given varied forms of stressors and experiences of the resultant stress due to COVID 19 pandemic, the adolescents could be particularly vulnerable to specific mental health facets. In this backdrop there have been studies on stress, depression, and anxiety amongst people, including adolescents and adults, but most of them were conducted during the phase of 'outbreak' or 'lockdowns' ${ }^{[8-12]}$. To the best of the author's knowledge, these studies have neither covered comprehensive mental health outcomes in adolescents in a single research design nor provided a comparative analysis by comparing them with adults.

Hence, it was considered pertinent to explore how adolescents differed from adults regarding the comprehensive mental health facets amid the 'new normal' phase, i.e., the duration between the first and second wave of COVID-19 in a developing country like India. The present study aimed to compare adolescents, young and middle-aged adults with comprehensive mental health facets (depression, anxiety, anger, repetitive thoughts and actions, somatic complaints, personality disturbances, memory, sleep problems, dissociation, suicidal ideation and substance use). Also, it aimed to explore the associations of mental health facets with age, perceived stress, coping and impact of pandemic. It was hypothesized that [1] adolescents would differ from adults on the comprehensive mental health facets [2] there would be an association of mental health facets with age, perceived stress, coping and impact of COVID 19 pandemic.

\section{Methods}

\section{Participants and study characteristics:}

This study employed a cross-sectional design by using a standardized tools through an online platform. It was part of an institutional project on mental health aspects during the pandemic. The proforma contained an assent form for adolescents and a consent form for adults, approved by the institute ethics committee. The ethical approval for conducting the study was obtained from the institutional ethics committee (ref code: 11th ECM COVID-19 1B/P7).

The study population comprises adolescents and adults between 13 to 60 years of age. All participants were selected by using a two-stage sampling technique. In the first stage, schools/ colleges were selected, and in the second stage, participants were recruited from the selected schools/ colleges. They were further categorized as [a] adolescents ( $\mathrm{Ad}=13-19$ years), [b] young adults $(\mathrm{Y}=20-39)$ and [c] middle-age adults (MA = 40-60 years of age). Five schools and five colleges were randomly selected from the city and contacted to participate in the study. Higher secondary schools and undergraduate/ postgraduate co-education colleges located within the city's urban limits were chosen.

\section{Procedure}

Three schools and four colleges agreed to participate in the study. The consenting school and college authorities were contacted for obtaining voluntarily informed consent to conduct a study in their institute and for coordination and implementation of data collection. The data collection was commenced on the noon of 1 st December and concluded on noon of 31 st December.

For the recruitment of adolescents, parents of the 13 to 18 years old adolescents were shared a consent form through email, which included information about the study, anonymity, and confidentiality. They were invited to give consent for the participation of their ward in the study. There was an option for parents to accept or decline the recruitment of their ward(s) in the study. After receiving the parents' consent, the assent form and 'the web link of study proforma' were mailed to the adolescents through email.

For the recruitment of adults, the web link of study proforma containing self-explanatory information about the study, informed consent form, questionnaire items, contact number, and official address of the investigators of the study, was disseminated through email to students of the colleges, parents, and staff of schools/colleges. All participants were provided contact numbers of the investigators for clarifications and were given an option to consent for an online interview. On a web link, participants got a set of questions in a sequential manner, which they had to answer by clicking on the given choices.

\section{Measures}

Semi-structured proforma: A self-explanatory web-based semi-structured proforma was developed, which was linked to a unique web link. This proforma collected sociodemographic information related to the participants [age, gender, education, occupation, and domicile]. For those who reported the presence of mental health symptoms, there were 3 items on whether 1- did not report any change in their symptoms and/or level of symptoms experienced during COVID192 -. the symptoms worsened during the pandemic 3-. the symptoms started during the COVID-19 outbreak,

DSM-5 Self-Rated Level 1 Cross-Cutting Symptom Measure-9:[14] This tool was developed by the DSM-5 Task Force and Work Groups to review the mental systems in each patient. We used this measure assesses the presence and severity of mental health domains (depression, anxiety, anger, repetitive thoughts and actions, somatic complaints, personality disturbances, memory, sleep problems, dissociation, substance, suicidal ideation and substance use). The respondents are asked how much or how often they have been disturbed problems in the last 2 weeks $(0=$ none/never, $1=$ slight $/$ rare, $2=\mathrm{mild} / \mathrm{several}$ days, 3 
$=$ moderate/more than half the days, $4=$ severe/almost daily). Research evidence shows that the measure has good to excellent test-rested reliability, ${ }^{[15]}$ and good validity. ${ }^{[16]}$

Perceived Stress Scale (PSS): ${ }^{[17]}$ PSS measures the extent to which one appraises the situations of one's life as stressful in the last month. It can be used in samples with minimum educational qualification of junior high school. It is a 10 item 5 -point Likert scale $(0=$ never, $1=$ almost never, $2=$ sometimes, $3=$ fairly often, 4 = very often). PSS-10 shows a strong Cronbach's alpha $=0.84$, with test-retest - reliability (ICC) to be 0.935 after three weeks and Kappa's Coefficient ranging from 0.74 to $0.89 .{ }^{[18,19]}$

Brief COPE: ${ }^{[20]}$ Brief COPE is a self-report questionnaire with 28 items designed to assess individuals' primary ways to cope with a stressful life event. The coping strategies were categorized as "adaptive" (active coping, use of emotional support, use of instrumental support, positive reframing, planning, selfdistraction, and acceptance) and "maladaptive" (behavioral disengagement, venting, denial, substance use, and self-blame) for this study. After taking due cognizance of the sociocultural backdrop of India, an item on religion was included. The items are rated on a four-point Likert scale ( $1=\mathrm{I}$ haven't been doing this at all, 2 = I have been doing this a little bit, 3 = I have been doing this a medium amount, 4 = I've been doing this a lot). The individual scores for each subscale is, then, computed by adding scores on all the items separately. The scale has shown high Cronbach's alpha values ranging from 0.69 to 0.8 . [21]

\section{Data analysis}

The results were analyzed using descriptive statistics and making comparisons among various groups. The analyses were performed using SPSS version 23.0 (SPSS Inc., Chicago, IL, USA). Categorical data were summarized as proportions and percentages (\%) and discrete as mean and standard deviations (SD). Given the non-parametric nature of data, the difference between groups was analyzed using the Chi-Square Test of Independence and correlational analysis was done using Spearman Rank Correlation. Multiple regression analyses were performed for the mental health facets along with bootstrapping method.

\section{Results}

A total of 1,027 participants have taken part in the study including 456 adolescents $(M=200 ; F=256) ; 347$ young adults $(M=124 ; F=223)$ and 224 middleaged adults $(M=103 ; F=121)$. The mean age of male females was found to be comparable among all across the groups. In the adolescent age group majority were students of intermediate (Table 1-a). 
Table 1

Socio-Demographic Characteristics of the Study Participants.

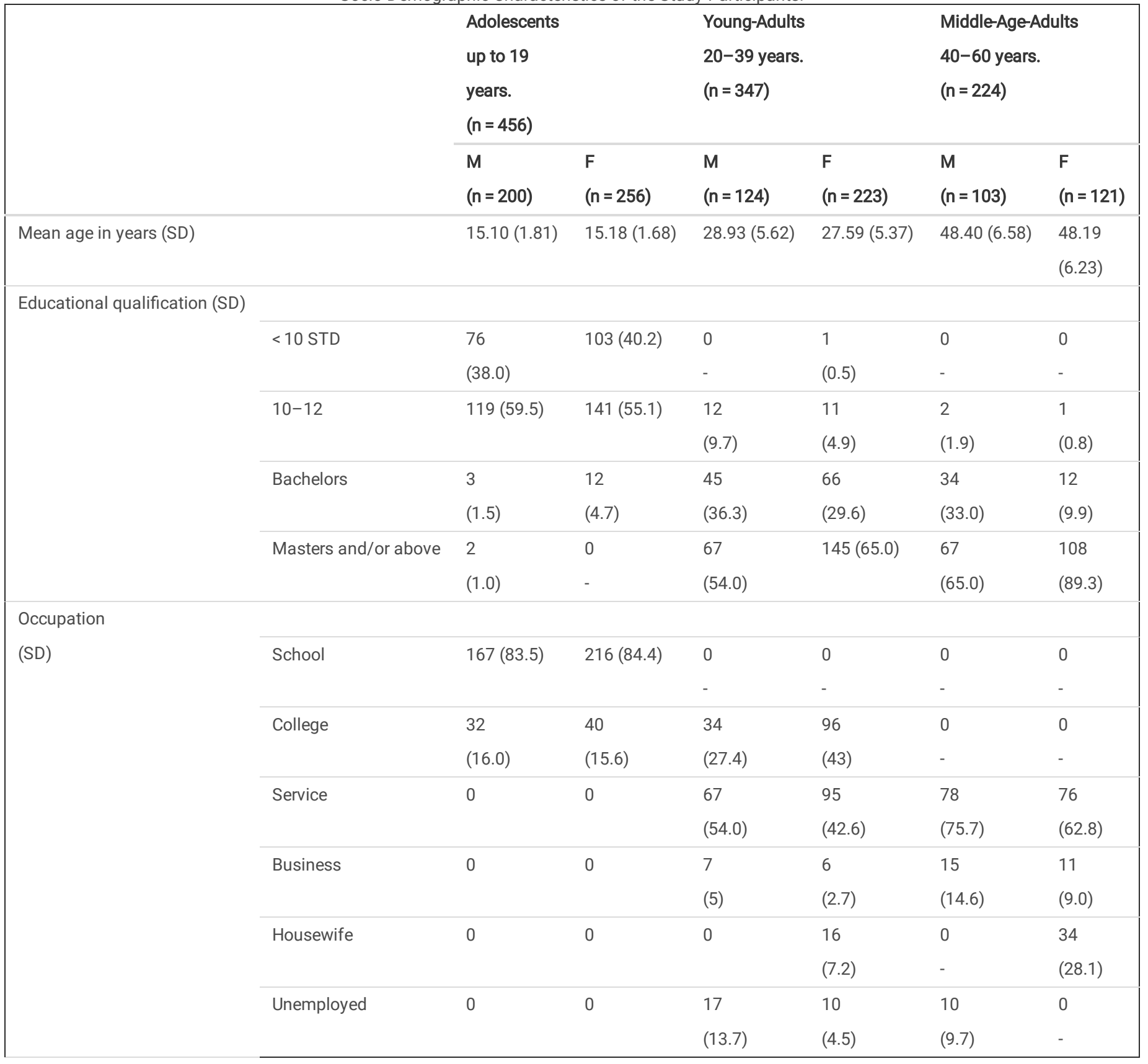


Table 2

Comparisons of comprehensive mental health facets across age and gender groups

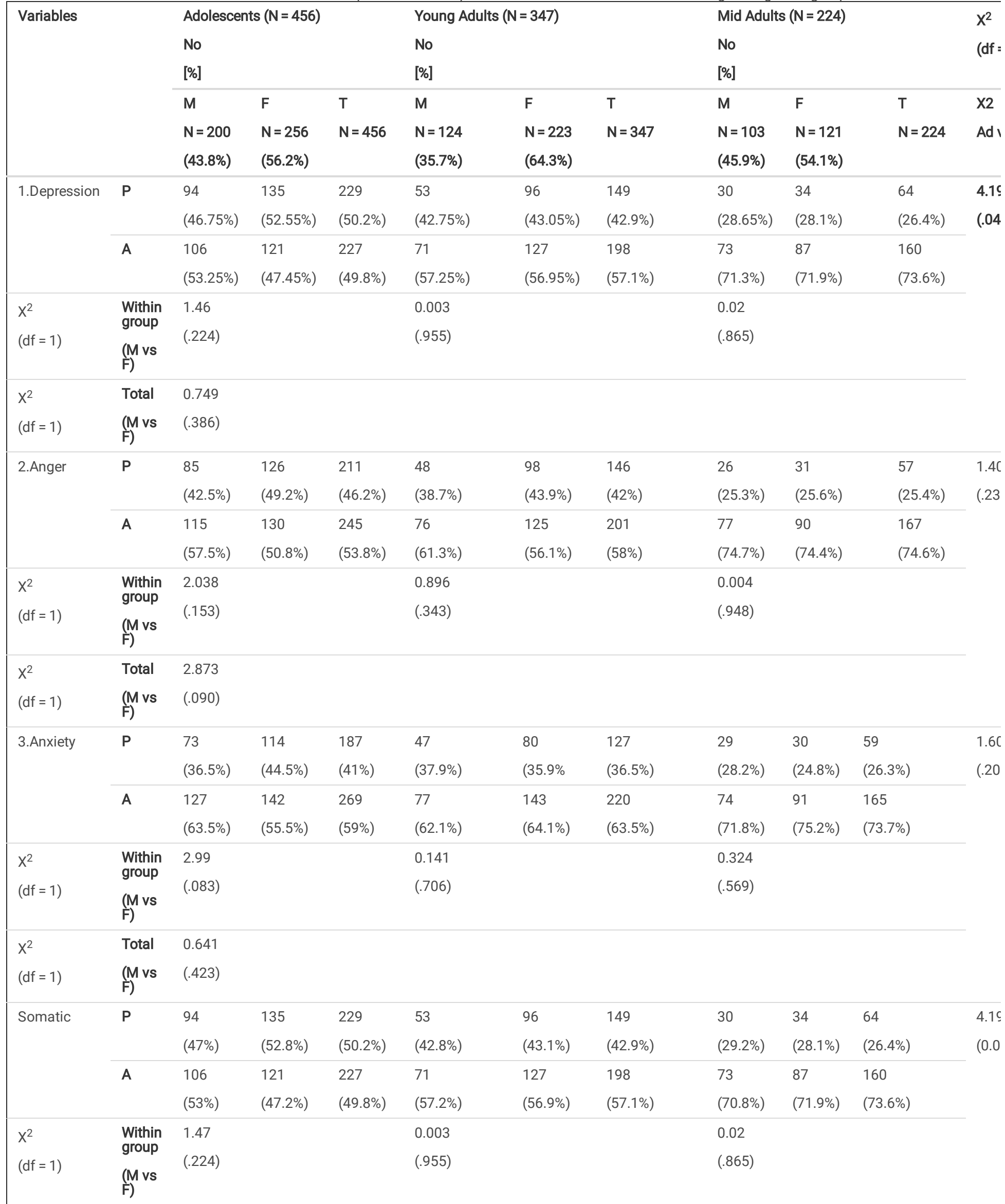




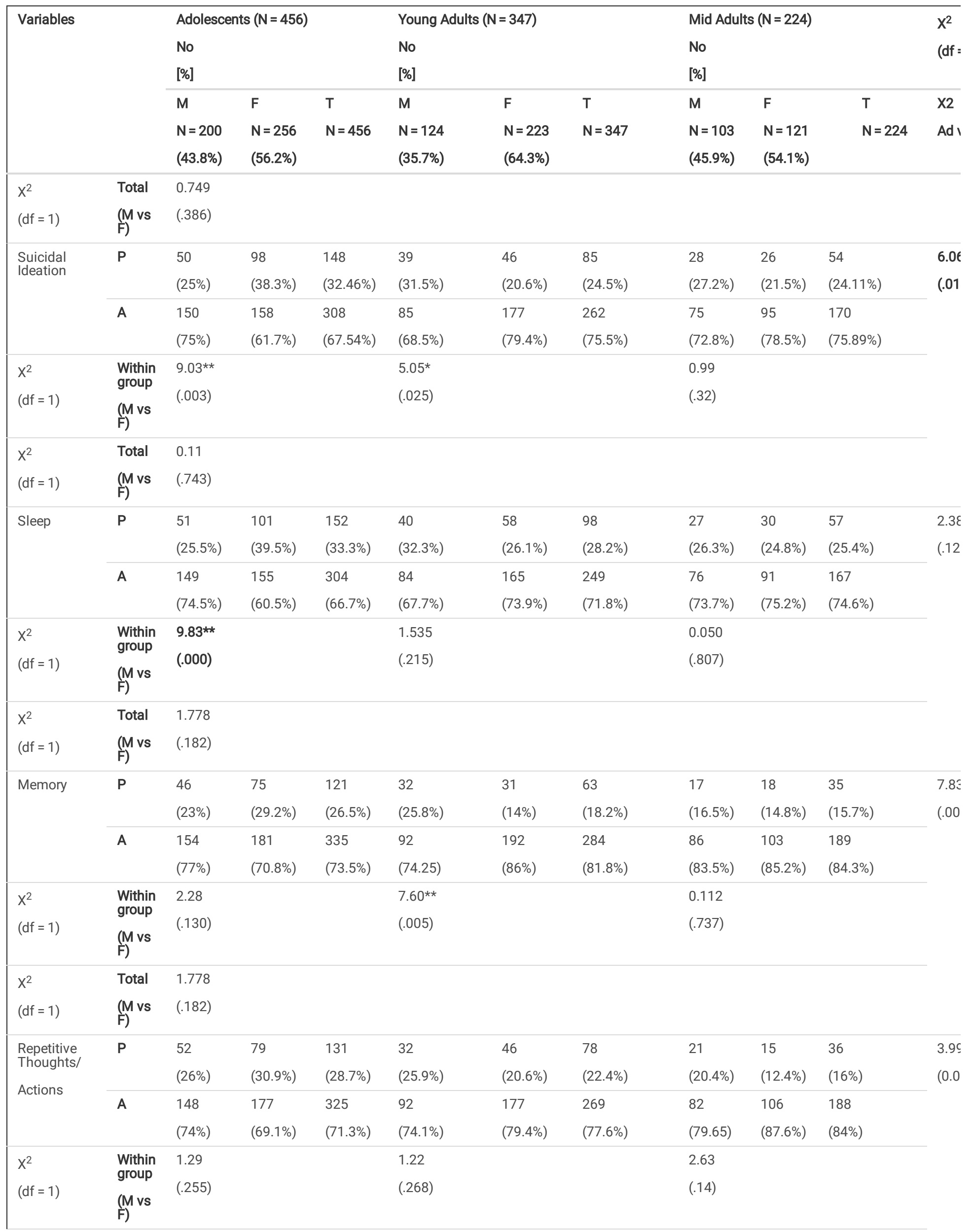




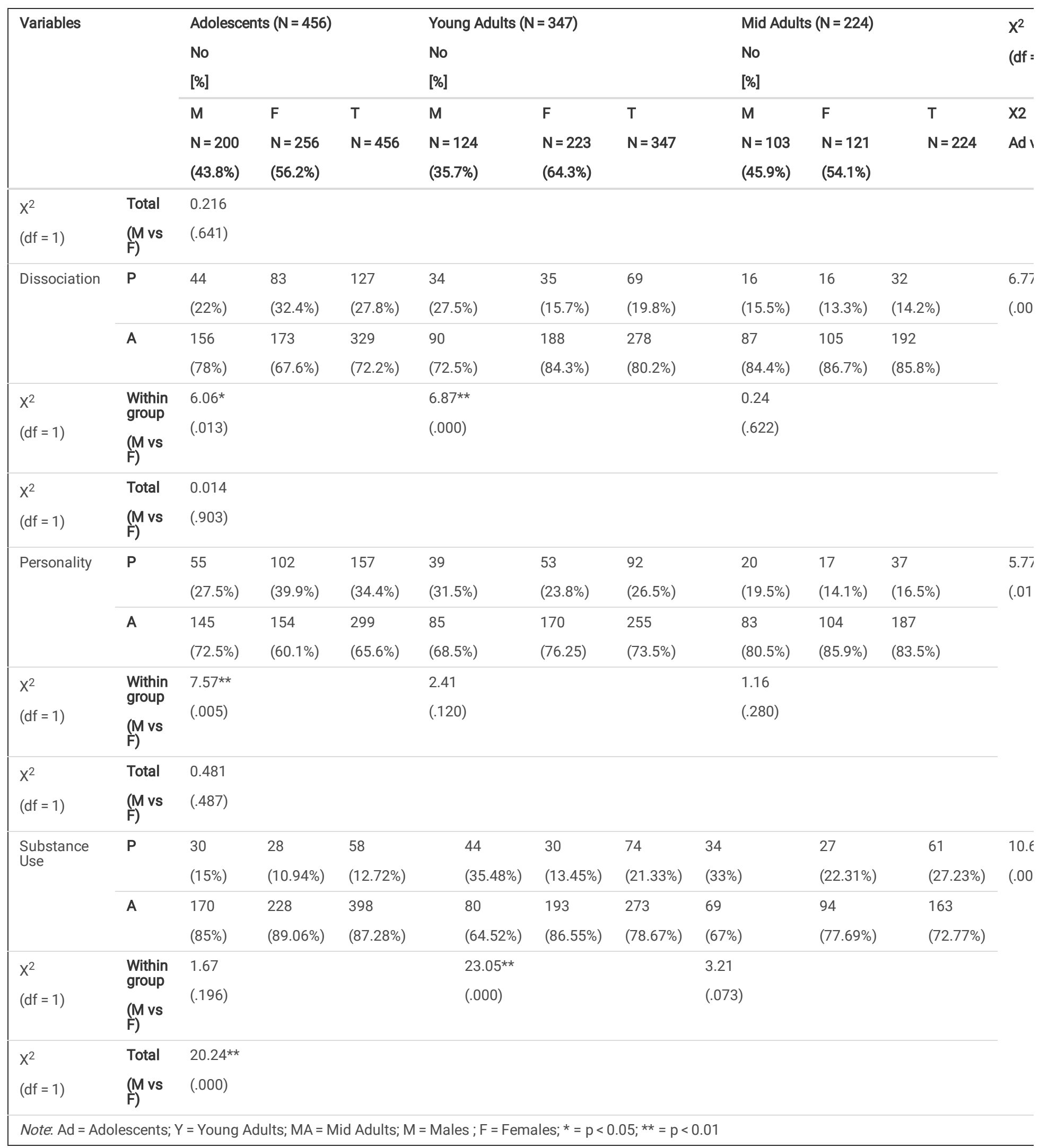

Table 3. Correlations between Mental Health Domains, Coping and Perceived Stress 


\begin{tabular}{|c|c|c|c|c|c|c|c|c|c|}
\hline Correlates & Depression & Anxiety & $\begin{array}{l}\text { Somatic } \\
\text { Concem }\end{array}$ & $\begin{array}{l}\text { Repetitive } \\
\text { Thoughts }\end{array}$ & $\begin{array}{l}\text { Personality } \\
\text { Changes }\end{array}$ & $\begin{array}{l}\text { Suicidal } \\
\text { Ideations }\end{array}$ & Sleep & Memory & $\begin{array}{l}\text { Substance } \\
\text { Use }\end{array}$ \\
\hline Substance Use & $.243^{\star *}$ & $.297^{\star *}$ & $.370^{\star *}$ & $.404^{\star *}$ & $.360 * \star$ & $.451^{\star *}$ & $.372^{\star *}$ & .397 & 1 \\
\hline Perceived Stress & $.587 \star \star$ & $.601 \star \star$ & $.445^{\star \star}$ & $.490 \star \star$ & $.523^{\star \star}$ & $.425^{\star}$ & $.418^{\star \star}$ & $.386 \star \star$ & $.96^{\star}$ \\
\hline Adaptive Coping & .052 & .110 ** & 0.50 & .015 & -.014 & -.031 & .001 & -.001 & .022 \\
\hline Maladaptive Coping & $.352^{\star *}$ & $.382^{\star *}$ & $.352^{\star *}$ & $.415^{\star \star}$ & $.432^{\star *}$ & $.431^{\star *}$ & $.338^{* *}$ & $.347^{* *}$ & $.359 * *$ \\
\hline Age & $-.176^{\star \star}$ & $-.090 \star \star$ & -.028 & $-.086^{\star \star}$ & $-.104^{\star *}$ & $-.082^{\star \star}$ & -.038 & $-.074^{\star}$ & $.139 * \star$ \\
\hline Impact of COVID & $.348^{\star *}$ & $.302^{\star \star}$ & $.270 * \star$ & $.289 \star *$ & $.295^{\star \star}$ & $.228^{\star \star}$ & $.233^{\star *}$ & $.251^{\star \star}$ & $.062^{\star}$ \\
\hline
\end{tabular}

Note: ${ }^{*}=p<0.05 ; * \star=p<0.01 ; * \star *=p<0.00$ 
Table 4

Regression Analysis

\begin{tabular}{|c|c|c|c|c|c|c|c|}
\hline Outcome Variable & Predictor Variable & $\beta$ & $t$ & $\mathbf{R}$ & $\mathrm{R}^{2}$ & $\mathbf{F}$ & S.E. \\
\hline \multirow[t]{10}{*}{ Depression } & Model & & & .614 & .367 & $38.125^{\star \star \star}$ & .059 \\
\hline & Perceived Stress & .310 & $10.982^{\star \star}$ & & & & \\
\hline & Impact of COVID & .148 & $5.518 * \star$ & & & & \\
\hline & Self-Distraction & .145 & $5.126 * \star$ & & & & \\
\hline & Self-Blaming & .134 & $4.361^{\star \star}$ & & & & \\
\hline & Religion & -.114 & $-3.887 * \star$ & & & & \\
\hline & Age & -.092 & $-3.411 * \star$ & & & & \\
\hline & Behavioural Disengagement & .098 & $3.213^{\star \star}$ & & & & \\
\hline & Emotional Support & -.078 & $-2.611 \star \star$ & & & & \\
\hline & Denial & .063 & $2.250 *$ & & & & \\
\hline \multirow[t]{8}{*}{ Anxiety } & Model & & & .631 & .389 & $41.827^{\star \star \star}$ & .063 \\
\hline & Perceived Stress & .332 & $11.977^{\star \star}$ & & & & \\
\hline & Self-Blaming & .196 & $6.493^{\star \star}$ & & & & \\
\hline & Self-Distraction & .156 & 5.628 ** & & & & \\
\hline & Impact of COVID & .113 & $4.273^{\star *}$ & & & & \\
\hline & Behavioural Disengagement & .120 & $4.011^{\star \star}$ & & & & \\
\hline & Religion & -.078 & $-2.681^{\star}$ & & & & \\
\hline & Emotional Support & -.063 & $-2.133^{\star}$ & & & & \\
\hline \multirow[t]{8}{*}{ Suicidal Ideation } & Model & & & .534 & .274 & 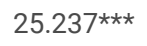 & .068 \\
\hline & Self-Blaming & .265 & $8.069 * \star$ & & & & \\
\hline & Behavioural Disengagement & .144 & $4.415^{\star \star}$ & & & & \\
\hline & Perceived Stress & .103 & $3.399 * *$ & & & & \\
\hline & Active Coping & -.089 & $-2.786^{\star}$ & & & & \\
\hline & Denial & .084 & $2.786^{\star}$ & & & & \\
\hline & Self-Distraction & .079 & $2.623^{\star}$ & & & & \\
\hline & Impact of COVID & .063 & $2.178^{*}$ & & & & \\
\hline \multirow[t]{9}{*}{ Anger } & Model & & & .644 & .406 & $44.786^{\star \star \star}$ & .060 \\
\hline & Perceived Stress & .326 & $11.941^{\star \star}$ & & & & \\
\hline & Self-Blaming & .170 & $5.705^{\star \star}$ & & & & \\
\hline & Self-Distraction & .150 & $5.503^{\star \star}$ & & & & \\
\hline & Impact of COVID & .131 & $5.023^{\star \star}$ & & & & \\
\hline & Age & -.082 & $-3.134^{\star \star}$ & & & & \\
\hline & Behavioural Disengagement & .084 & $2.865^{\star \star}$ & & & & \\
\hline & Gender & .053 & $2.109 *$ & & & & \\
\hline & Emotional Support & -.060 & $-2.076^{\star}$ & & & & \\
\hline \multirow[t]{6}{*}{ Somatic Concern } & Model & & & .504 & .242 & $21.482^{\star \star \star}$ & .060 \\
\hline & Perceived Stress & .212 & $6.881^{\star \star}$ & & & & \\
\hline & Impact of COVID & .122 & $4.143^{\star \star}$ & & & & \\
\hline & Self-Blaming & .123 & $3.659 * *$ & & & & \\
\hline & Self-Distraction & .097 & $3.151^{\star \star}$ & & & & \\
\hline & Behavioural Disengagement & .121 & $3.096 * \star$ & & & & \\
\hline
\end{tabular}

Page 10/20 


\begin{tabular}{|c|c|c|c|c|c|c|c|}
\hline Outcome Variable & Predictor Variable & $\beta$ & $\mathrm{t}$ & $\mathbf{R}$ & $\mathrm{R}^{2}$ & $\mathbf{F}$ & S.E. \\
\hline & Emotional Support & -.102 & $-3.096 * \star$ & & & & \\
\hline & Religion & -.087 & $-2.711^{\star}$ & & & & \\
\hline & Substance Use as Coping & .079 & $2.558^{\star}$ & & & & \\
\hline & Gender & .067 & $2.349 *$ & & & & \\
\hline \multirow[t]{7}{*}{ Sleep Problem } & Model & & & .470 & .208 & $17.854 * \star \star$ & .059 \\
\hline & Perceived Stress & .193 & 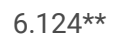 & & & & \\
\hline & Self-Blaming & .138 & $4.033^{\star *}$ & & & & \\
\hline & Self-Distraction & .104 & $3.286^{\star \star}$ & & & & \\
\hline & Religion & -.105 & $-3.188^{\star \star}$ & & & & \\
\hline & Behavioural Disengagement & .103 & $3.039 * *$ & & & & \\
\hline & Impact of COVID & .086 & $2.866^{\star \star}$ & & & & \\
\hline \multirow[t]{6}{*}{ Memory } & Model & & & .468 & .219 & $17.749 * \star \star$ & .065 \\
\hline & Self-Blaming & .214 & $6.228 * \star$ & & & & \\
\hline & Perceived Stress & .138 & $4.369 \star \star$ & & & & \\
\hline & Impact of COVID & .112 & 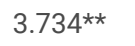 & & & & \\
\hline & Religion & -.077 & $-2.332^{\star}$ & & & & \\
\hline & Self-Distraction & .070 & $2.228^{*}$ & & & & \\
\hline \multirow[t]{9}{*}{ Repetitive Thoughts/Actions } & Model & & & .569 & .313 & $30.281^{\star \star \star}$ & .064 \\
\hline & Self-Blaming & .241 & $7.528 \star \star$ & & & & \\
\hline & Perceived Stress & .182 & $6.197 \star \star$ & & & & \\
\hline & Behavioural Disengagement & .149 & $4.690^{\star \star}$ & & & & \\
\hline & Self-Distraction & .106 & $3.601^{\star \star}$ & & & & \\
\hline & Impact of COVID & .098 & $3.506^{\star \star}$ & & & & \\
\hline & Religion & -.090 & $-2.923^{\star \star}$ & & & & \\
\hline & Denial & .082 & $2.803^{*}$ & & & & \\
\hline & Emotional Support & -.082 & $-2.616^{\star}$ & & & & \\
\hline \multirow[t]{9}{*}{ Personality Disturbances } & Model & & & .633 & .391 & $42.211^{\star \star \star}$ & .065 \\
\hline & Self-Blaming & .312 & $10.358^{* \star}$ & & & & \\
\hline & Perceived Stress & .222 & $8.031^{\star \star}$ & & & & \\
\hline & Behavioural Disengagement & .159 & $5.330 \star \star$ & & & & \\
\hline & Emotional Support & -.128 & $-4.330 * \star$ & & & & \\
\hline & Religion & -.100 & $-3.458 \star \star$ & & & & \\
\hline & Self-Distraction & .093 & $3.369 * *$ & & & & \\
\hline & Impact of COVID & .056 & $2.112^{\star}$ & & & & \\
\hline & Age & -.051 & $-1.918^{*}$ & & & & \\
\hline \multirow[t]{7}{*}{ Dissociation } & Model & & & .548 & .289 & $27.082^{\star \star \star}$ & .067 \\
\hline & Self-Blaming & .232 & $7.145^{\star \star}$ & & & & \\
\hline & Behavioural Disengagement & .182 & $5.642^{\star *}$ & & & & \\
\hline & Perceived Stress & .153 & $5.134^{\star \star}$ & & & & \\
\hline & Impact of COVID & .098 & $3.443^{\star \star}$ & & & & \\
\hline & Emotional Support & -.092 & $-2.891^{\star \star}$ & & & & \\
\hline & Religion & -.082 & $-2.634^{\star}$ & & & & \\
\hline
\end{tabular}




\begin{tabular}{|c|c|c|c|c|c|c|c|}
\hline Outcome Variable & Predictor Variable & $\beta$ & $\mathrm{t}$ & $\mathbf{R}$ & $\mathrm{R}^{2}$ & $\mathrm{~F}$ & S.E. \\
\hline & Self-Distraction & .074 & $2.485^{\star}$ & & & & \\
\hline \multirow[t]{5}{*}{ Total Substance Use } & Model & & & .481 & .220 & $19.035^{\star \star \star}$ & .104 \\
\hline & Substance Use as Coping & .371 & $11.903^{\star \star}$ & & & & \\
\hline & Denial & .093 & $2.980^{\star \star}$ & & & & \\
\hline & Perceived Stress & .072 & $2.306^{\star}$ & & & & \\
\hline & Positive Reframing & -.069 & $-2.096^{\star \star}$ & & & & \\
\hline \multicolumn{8}{|c|}{$\begin{array}{l}\text { Note: Model = Self-Distraction, Denial, Substance Use as Coping, Positive Reframing, Self-Blaming, Behavioural Disengagement, Active Coping, Emotional } \\
\text { Support, Instrumental Support, Religion, Acceptance, Venting, Perceived Stress, Age, Gender, Impact of COVID }\end{array}$} \\
\hline
\end{tabular}

\section{Comparison of mental health facets among adolescents and adults}

Our results show that among those who had significant problems, $33.77 \%$ of adolescents, $25.65 \%$ of young adults, and $17.41 \%$ of middle-aged adults reported that their symptoms started during the pandemic. Whereas, $20.61 \%$ of adolescents, $21.04 \%$ young adults, and $11.61 \%$ middle-age adults reported worsening symptoms during the pandemic.

Depression- Significantly higher $(\mathrm{p}<0.05)$, percentages of Adolescents were $(50.2 \%)$ found to have depression compared to young adults $(42.9 \%)$ and middleaged adults $(26.4 \%)$, with $14 \%, 8.7 \%$, and $3.4 \%$ respectively reporting Severe symptoms.

Anger-Significantly $(p<0.01)$ higher percentages of Adolescents $(46.2 \%)$ and young adults $(42.0 \%)$ were found to have anger compared to middle-aged adults (25.4\%), with $15.1 \%, 7.7 \%$, and $4.4 \%$ respectively reporting Severe symptoms.

Anxiety- $36.5 \%$ of Young Adults and $26.3 \%$ of Middle Age Adults reported significant anxiety levels, with $13.1 \%, 11.5 \%$, and $5.8 \%$ respectively reporting Severe symptoms.

Suicidal Ideation: Significantly higher percentages of adolescents i.e., $32.46 \%, 24.5 \%$ of Young Adults, and $24.11 \%$ of Middle Age Adults, reported significant levels of Suicidal Ideation, with $8.11 \%, 4.61 \%$, and $1.34 \%$ respectively reporting Severe symptoms.

Somatic Complaints- $50.2 \%$ of Adolescents, $42.9 \%$ of Young Adults, and $26.4 \%$ of Middle Age Adults reported significant levels of Somatic Complaints, with $14 \%, 8.7 \%$, and $3.4 \%$ respectively reporting Severe symptoms.

Sleep $-33.3 \%$ of Adolescents, $28.2 \%$ of Young Adults, and $25.4 \%$ of Middle Age Adults reported significant sleep disturbances, with $10.3 \%, 8.5 \%$, and $4.9 \%$ respectively reporting Severe symptoms.

Memory - In the memory domain, significant differences were found between Adolescents and Young Adults were $26.5 \%$ of Adolescents, $18.2 \%$ of Young Adults, and $15.7 \%$ of Middle Age Adults reported significant levels of Memory problems, with $9.21 \%, 4.32 \%$, and $2.68 \%$ respectively reporting Severe symptoms.

Repetitive Thoughts/Behaviours- Higher percentages of adolescents i.e., 28.7\%, 22.4\% of Young Adults, and 16.4\% of Middle Age Adults, reported significant Repetitive Thoughts and Actions $12.3 \%, 6 \%$, and $2.1 \%$, respectively, reporting Severe symptoms.

Dissociative experience $27.8 \%$ of Adolescents, $19.8 \%$ of Young Adults, and $14.2 \%$ of Middle Age Adults reported significant levels of dissociation, with $12.1 \%$, $4.6 \%$, and $1.7 \%$ respectively reporting Severe symptoms.

Personality Changes- Significantly higher percentages of Adolescents (34.4\%), 26.5\% of Young Adults, and 16.5\% of Middle Age Adults reported some form of Personality Disturbances, with $14.7 \%, 8.1 \%$, and $2.2 \%$ respectively reporting Severe symptoms.

Substance use: Our results showed that compared to Adolescents (12.72\%), a significantly higher proportion of Young Adults (21.33\%) and Middle Age Adults (27.23\%) reported being bothered due to some or the other substance use including alcohol, tobacco or other drugs. 3.1\% Adolescents, $6.1 \%$ Young Adults, and $3.6 \%$ Middle Age Adults reported Sever level of symptoms.

\section{Gender wise analysis of mental health facets:}

The differences between males and females in mental health facets were statistically insignificant on most domains, i.e., depression, anger, anxiety, somatic complaints, suicidal ideation, repetitive thoughts and actions, dissociation, memory, and personality disturbances. Among those who reported symptoms, our results show that $28.57 \%$ of males and $26.67 \%$ of females reported that their symptoms started during the pandemic. In addition, $18.97 \%$ of males and $18.67 \%$ of females reported worsening of symptoms during the COVID19 pandemic.

Depression: Table 2 shows that $41.5 \%$ of Males and $44.2 \%$ of Females reported significant symptoms. 
Anger: Table 2 shows that $36.8 \%$ of Males and $46.5 \%$ of Females reported significant symptoms.

Anxiety: 34.9\% Males and 37.4\% Females reported significant symptoms.

Somatic Complaints: $41.2 \%$ Males and $44.2 \%$ Females reported significant symptoms.

Sleep - Significantly higher percentages of females (39.9\%) in the adolescent group were found to have sleep disturbances compared to their counterparts (25.5\%), with $27.7 \%$ Males and $31.5 \%$ Females reported significant symptoms. Moreover, $36.8 \%$ of Males and $46.5 \%$ of Females reported significant symptoms.

Suicidal Ideation: $27.4 \%$ Males and 28.33\% Females reported suicidal ideations.

Memory - No overall gender variation was found; however, within Young Adults, more males (25.8\%) reported memory problems than females (14\%). Moreover, $27.7 \%$ of Males and $31.7 \%$ of Females reported significant symptoms.

Repetitive Thoughts/Behaviours- 22.1\% Males and 22.4\% Females reported significant symptoms.

Dissociative experience- $24.6 \%$ Males and $23.4 \%$ Females reported significant symptoms. Significantly $(p<0.01)$, higher percentages of females $(32.4 \%)$ in the adolescent group and males in the young adult (27.5\%) group were found to have dissociative experiences as compared to their counterparts (22.0\% \& $15.7 \%$ respectively).

Personality Disturbance- $26.7 \%$ Males and 28.7\% Females reported significant symptoms. Significantly higher percentages of females (39.9\%) in adolescent groups were found to have personality changes compared to their counterparts (27.5\%).

Substance use: Males and Females also differed with more Males (25.29\%) reported Substance Use compared to Females (14.17\%) where 5.4\% Males and 3.3\% Females reported Severe symptoms. Gender differences were found within the Young Adult group as well, with Males (35.48\%) reporting more substance use than their Female (13.45\%) counterparts.

\section{Correlations between Mental Health, Age, Coping and Perceived Stress.}

The correlational analysis showed 'age' was negatively associated with depression anxiety, repetitive thoughts, personality changes, suicidal ideations and memory, and positively associated with 'substance use' at low levels. There was moderate positive correlations between perceived stress and all the mental health domains. All mental health domains, except substance use showed moderate-to-low correlations with 'Impact of COVID'. Moreover, substance use itself showed moderate positive correlations with other mental health domains. Maladaptive coping was moderately positively correlated with all the mental health domains whereas adaptive coping showed only low positive correlation with anxiety.

\section{Regression Analysis}

The regression analyses show that coping strategies, perceived stress, age, gender and impact of COVID provide a significant model for prediction of depression, anxiety, suicidal ideation and substance use. Perceived stress, impact of COVID, self-distraction, self-blaming were significant independent positive predictors for all the mental health domains except substance use. Behavioural disengagement also showed positive association with depression, anxiety, suicidal ideation, anger, somatic concern, sleep, repetitive thoughts, personality disturbances and dissociation. Emotional support and Religion were negative independent predictors for depression, anxiety, suicidal ideation, repetitive thoughts, personality disturbances, somatic concern and dissociation; and Anger was also predicted by Emotional Support. Denial was a significant independent predictor for depression and repetitive thoughts and actions, and gender was an independent predictor for anger and somatic concern. Suicidal ideation also had active coping with negative association. Positive reframing was in a negative relation with substance use and denial, perceived stress, substance use as coping were significant independent predictors for maladaptive substance use. In addition, age was a significant independent predictor for depression, anger and personality disturbances with negative association.

The regression analyses show that coping strategies, perceived stress, age, gender and impact of COVID provide a significant model for prediction of depression, anxiety, suicidal ideation and substance use. Perceived stress, impact of COVID, self-distraction, self-blaming, religion, age, behavioural disengagement, emotional support and denial were significant independent predictors for depression and anxiety, where emotional support and religion were negatively associated. In addition, age and denial were significant independent predictors for depression, where age was negatively associated. Suicidal ideation also had self-blaming, behavioural disengagement, perceived stress, active coping, denial, self-distraction, impact of COVID as significant independent predictors, where active coping was negatively associated. Positive reframing was in a negative relation with substance use and denial, perceived stress, substance use as coping were significant independent predictors for maladaptive substance use.

\section{Discussion}

The current study was conducted to compare comprehensive facets of mental health reactions and their association with age, stress and coping among adolescents and adults amid the "New Normal Pandemic era". Mental Health status across all age groups and genders revealed that the pandemic played a significant role in the mental health of participants. The feelings of depression and sadness [mild to severe] were the most prevalent complaints among Adolescents amid the pandemic. Moreover, a significantly large proportion of the sample reported suicidal ideations, which is consistent with the literature, suggesting statistically significant relations between pandemic stress and suicidal ideations. ${ }^{[22]}$

This detrimental effect was specifically suggested by the high percentage of adolescent population reporting an absence of the symptoms before the COVID19 outbreak. Taking into account the mental health facets of DSM-5 Self-Rated Level 1 Cross-Cutting Symptom Measure, it was observed that increased stress 
owing to the virus and its impact on individuals' social, occupational, and academic life led to more individuals reporting depression, anxiety, somatic concerns, obsessive thoughts and drives, suicidal ideations, sleep problems, memory problems, and personality issues.

\section{Comparisons among adolescents and adults:}

Adolescence is marked by a period of "storm and stress", social sensitivity, and a need for independence. In our study, a general decreasing trend was observed with increase in age across most of the mental health indicators i.e. Ad $>$ Y > MA for Depression, Somatic Complaints, Suicidal Tendencies and Personality Issues, Ad \&Y > MA for Anger and Anxiety, and Ad > Y\&MA for Repetitive Thoughts and Actions and Dissociation, suggesting that Adolescents had more significant symptoms with a need for further professional assessment and treatment. This trend is the opposite of the overall prevalence indicated in the National Mental Health Survey, which estimated higher mental morbidity in middle-aged individuals (40-49 years age group). ${ }^{[23,24]}$ Adolescents' depression point prevalence at $0.1-6.94 \%$ in community studies and $1.2 \%-21 \%$ in the clinic-based studies, ${ }^{[25]}$ and a crude prevalence of depressive disorders and anxiety disorders in adults at around 3.3\%. ${ }^{[26]}$ During the pandemic, adolescents were particularly distressed with being socially disconnected from their friends, and illness-related worries along with educational difficulties can be significantly associated with depression, anxiety, and life satisfaction, ${ }^{[27,28]}$ making adolescents specifically vulnerable.

While pre-pandemic suicide risk, according to the National Mental Health Survey, increased from the age group of $18-29$ years to $50-59$ years. ${ }^{[23]}$ During the pandemic, adolescents reported more suicidal tendencies. This could be attributed to the current pandemic being a major stressful life event and related experiences (such as a fatal threat for life and health and the effect of social distancing policies), which can be a significant risk factor for adolescents suicidality. ${ }^{[29]}$ Mid adults report lesser deterioration of the sleep quality than adolescents as the pandemic had a more significant impact on adolescents' social interactions and education and caused them more significant anxiety, which led to disturbances in sleep such as difficulties initiating and maintaining sleep. ${ }^{[28,30]}$

More adolescents with personality issues were found in our sample, which is explainable given that adolescence is the age for resolving Eriksonian conflict of "identity vs role confusion". This resolution involves the exploration of roles, which was restricted during the pandemic. Hence, the emotional detriment caused during the lockdown leads to lower self-concept values than before the restrictions. ${ }^{[31]}$ Higher somatic complaints in adolescents can be understood as stemming from three types of concerns - the threat to life and health posed by COVID-19, daily life necessities, and efficacy of prevention and control measures. ${ }^{[32]}$ These concerns may be lesser in the older population due to higher perceived self-efficacy in times of crisis. ${ }^{[33]}$

In our sample, substance abuse (drinking, smoking, and other drugs) was reported by more Adults than Adolescents, which is aligned with various studies which suggest that the overall rate of alcohol drinking and smoking increased only marginally during the COVID-19 pandemic, however, the frequency of use increased substantially. Hence, substance use did not increase in the form of initiation by Adolescents but in regular drinkers and regular smokers, and as a relapse in ex-drinkers and ex-smokers. ${ }^{[34,35]}$

\section{Comparisons among males and females:}

Similar to previous studies, ${ }^{[7,9]}$ our findings posit that there is no significant gender difference in most of the mental health correlates, except substance abuse - where more Males reported a high intake of substance compared to Females. This is an interesting finding as the National Mental Health Survey delineated that Males had a higher prevalence of mental morbidity in the pre-pandemic era. ${ }^{[23]}$ Therefore, the lack of significant difference between genders highlights the importance of the COVID-19 pandemic as a significant stressor. However, substance use trends are similar to the pre-Covid mental health findings since externalizing disorders such as alcohol, drug abuse, and antisocial behavior are more predominant in men than existing cultural script. ${ }^{[36]}$ Higher levels of substance use are also related to the Asian cultural value of masculinity and are, therefore, widely used as a form of coping in Asian men. ${ }^{\text {[37, 38] }}$

Within age groups, our study found significant differences in Suicidal Tendencies between Male and Female Adolescents, where more Females reported suicidal tendencies, and between Young Adult Males and Females, where more Males reported suicidal tendencies. Even pre-pandemic females had a higher risk of suicide than males due to gender discrimination, social exclusion, gender disadvantage. ${ }^{[23,39]}$ However, the higher number of Young Adult Males expressing suicidal tendencies is a notable change observed, which could be attributed to the externalization of their social and individual turmoil. The stress of probable unemployment due to the uncertainty during the pandemic could be a substantial risk factor for Young Adult Males due to the social meanings attached to work and the association between hegemonic masculinity and working. Moreover, our study also found that more Adolescent Females reported sleep disturbances that could be understood as a product of catastrophic worrying that Adolescent Females are susceptible to sleep problems compared to Adolescent Males.

A disaster or crisis, such as the COVID-19 pandemic, is potentially traumatic and imposes massive collective stress. Moreover, an individual's work environment, school environment, and family environment play important roles in the pathogenesis of mental disorders. ${ }^{[39]}$ Our study indicates a specific vulnerability of the younger population while adjusting to environmental stressors and highlights the pivotal role of the pandemic for individual mental health. Associations of Mental health facets:

The correlational analysis showed age to be negatively associated with depression, anxiety, and other mental health facets, and positively associated with substance use at lower levels. In our study, a general decreasing trend was observed with increase in age across most of the mental health indicators i.e. Ad > $\mathrm{Y}>\mathrm{MA}$. Literature during the pandemic has posited poorer resilience and emotional regulation in adolescents in times of crisis. ${ }^{[4,5,6,8,9,27]}$ 
There was moderate positive relations of mental health domains with perceived stress which is consistent with the literature that suggests that, regardless of the current level of adjustment for internal resources and social support, stress is consistently the strongest correlate of mental health. ${ }^{[40]}$ The specifically high correlation between substance abuse and stress can be explained by the tension-reduction hypothesis that suggests that exposure to stressors induces substance use as a means of mitigating experienced tension and strain. ${ }^{[41]}$ All mental health domains, except substance use showed moderate-to-low correlations with 'Impact of COVID 19'. [4, 5, 6, 8, 9, 27]

As expected, maladaptive coping was positively related to mental health domains and showed a moderate correlation with repetitive thoughts, personality disturbances as well as suicidal ideation. It has been observed that ruminative coping acts as a significant maladaptive strategy and perpetuated repetitive thoughts. ${ }^{[42]}$ Moreover, coping styles can mediate between a stressful situation and a negative outcome, like suicidal behavior. ${ }^{[43]}$

A vital and interesting finding was the lack of negative correlation between adaptive coping and mental health domains and a significant positive correlation between adaptive coping and anxiety. This can be associated with the high uncertainty during the pandemic and further explains the low positive correlation between adaptive coping and anxiety. This highlights the limitations of coping styles and re-emphasizes that various factors, like the nature of pandemic as a 'stressor' and the degree of stress experienced, can influence the relation between coping and mental health outcomes, which were particularly important during the pandemic. ${ }^{[44]}$ Being a problem-focused coping strategy, planning was included in 'adaptive coping style' in this study. However, planning can be associated with more severe anxiety symptoms during COVID-19. ${ }^{[45]}$

\section{Predictors of Mental Health facets:}

Our results show that coping strategies, perceived stress, age, gender and impact of COVID-19 provided a significant predictive model for depression, anxiety, suicidal ideation and maladaptive substance use. The independent predictors provide further clarity on the role of each variable.

Perceived stress was a significant and strong independent predictor across the four mental health facets. This is consistent with the literature that suggests that a stressful life event is a significant causal factor for the onset of depression and anxiety, and a stressful environment leads to more substance use. ${ }^{[46]}$ To a stressful situation, humans and animals produce a coping response, ${ }^{[46]}$ hence coping becomes extremely important while predicting mental illnesses. In our study, maladaptive coping strategies significantly positively predicted depression, anxiety, suicidal ideation and substance use, whereas adaptive coping strategies significantly negatively predicted the mental health facets.

Denial was a significant independent predictor for all four mental health facets, while self-blaming, behavioural disengagement and self-distraction positively predicted depression, anxiety and suicidal ideation but not substance use. Denial provides a form of escapism from a stressful situation, and can therefore lead to further worsening of mental health. Substance use particularly shows denial as an underlying form of cognitive process where an individual has a poor ability to modify the way of approaching a problem or identify and use a concept. ${ }^{[47]}$

Self-blame is primary feature of depression, according to A. T. Beck's cognitive theory. ${ }^{[48]}$ While self-blame can stimulate active coping, it can lead to further guilt and even depression ${ }^{[49]}$ as well as anxious rumination. Hence, self-blame can predict depression, anxiety and suicidal ideation.

Self-distraction and behavioural disengagement, both, provide an avoidant form of coping and are significant predictors of depression, anxiety and suicidal ideation. This result is in tandem with past researches ${ }^{[50]}$ and can be explained by the possibility that reliance on avoidance coping could generate a broad range of stressors where cognitive avoidance could permit growth of incipient stressors, and behavioural avoidance could actively promote new stressors, ${ }^{\text {[51] }}$ therefore resulting in poor mental health outcomes.

While research has found an association between coping through emotional support seeking and higher quality of life and general mood, ${ }^{[52]}$ interestingly, while emotional support was a significant negative predictor for depression and anxiety, it was not significant for suicidal ideation. Suicidal ideation, therefore, poses a special specific problem where an individual might be more sensitive to the potential rejection while seeking emotional support as is explained by the Interpersonal-Psychological Theory of suicide. ${ }^{[50]}$

The negative predictive association of religion as coping with depression and anxiety is consistent with past researches which suggest that positive religious coping is associated with positive psychological adjustment. ${ }^{[53]}$ This positive and adaptive involvement in religiosity can assist and equip individuals to understand the world, and allows effective appraisal and management of stressful situations, which was particularly important during a pandemic ${ }^{[53]}$. As mentioned above, the impact of COVID-19 on mental health has been severe, hence was also found a significant predictor for depression, anxiety and suicidal ideation.

\section{Conclusion}

The DSM-5 Cross-Cutting Measure provides the severity of symptoms, where levels mild and above are clinically significant for all disorders except substance use, suicidal ideation, and psychosis, where even a minimal level of severity is important for clinical decision-making through research. Based on our results, it is vital to note that around half of the Adolescents and Young Adults show clinically significant levels of Depression, Anger, and Somatic Complaints. $35 \%-45 \%$ of Adolescents and Young Adults reported anxiety, and $25 \%-35 \%$ reported suicidal ideations and sleep disturbances at clinically significant levels. A lower percentage (15\%-30\%) reported memory disturbances, repetitive thoughts, and dissociation. Among Adolescents and Young Adults, more severe symptoms were reported in Adolescents. Moreover, Middle-Aged Adults showed low clinically meaningful symptoms across domains (15\%-25\%). However, the clinical severity of substance use was more pronounced in Middle-Aged Adults compared to Adolescents and Young Adults. 
Therefore, it can be observed Adolescents are more clinically vulnerable in most domains. A significant amount of individuals from our sample require further clinical assessment and intervention, where Middle-Aged Adults should further be seen as a clinically vulnerable population for substance use during the pandemic. Hence, this study provides a comprehensive analysis for clinical decision-making and policy development to combat the mental health problems arising and exacerbating due to the COVID-19 pandemic.

Limitations:

The cross-sectional design of the study acts as a significant limitation as it provided data only within a single time frame and not throughout the pandemic. Most of the participants were residents of Uttar Pradesh, which could have affected the results from a cultural point of view. However, the large sample size, population representation, and weighting by age, sex, and region could reduce this limitation to an extent.

Conclusion:

The DSM-5 Cross-Cutting Measure provides the severity of symptoms, where levels mild and above are significant for all disorders except substance use, suicidal ideation, and psychosis. Even a minimal level of severity is essential for clinical decision-making through research. Based on our results, it is vital to note that around half of the Adolescents and Young Adults show significant levels of Depression, Anger, and Somatic Complaints. 35\%-45\% of Adolescents and Young Adults reported anxiety, and 25\%-35\% reported suicidal ideations and sleep disturbances at significant levels. A lower percentage of individuals (15\%-30\%) reported memory disturbances, repetitive thoughts, and Dissociation. Among Adolescents and Young Adults, more severe symptoms were reported in Adolescents.

Moreover, Middle-Aged Adults showed low significant symptoms across domains (15\%-25\%). However, the clinical severity of substance use was more pronounced in Middle-Aged Adults compared to Adolescents and Young Adults. Therefore, it can be observed that a significant amount of individuals from our sample require further clinical assessment and intervention, where Adolescents are more clinically vulnerable in all domains except substance use. MiddleAged Adults should further be seen as a clinically vulnerable population for substance use during the pandemic. Hence, this study provides a comprehensive analysis for clinical decision-making and policy development to combat the mental health problems in the backdrop of COVID-19 pandemic.

The ethical approval was obtained from the institutional ethics committee (ref code: 11th ECM COVID-19 1B/P7).

\section{Declarations}

\section{Acknowledgements}

Authors would like acknowledge help extended by the teachers and school and college authorities. Also, authors are grateful to all the participants for their active participation.

\section{Funding}

The project did not receive any financial support for the conduction of the study.

\section{Availability of data and materials}

The datasets used and/or analysed during the current study are available from

the corresponding author on reasonable request.

\section{Contributions}

SS conceptualized and coordinated the study. MD, SB \& SS analyzed the survey data, and SS, MD, SB, RT drafted the manuscript. RT, PG, PM, AA. AT, BG , $\mathrm{MM}, \mathrm{AN}, \mathrm{VA}, \mathrm{PKD}$ contributed significantly to the revision of the manuscript. All authors read and approved the final manuscript

\section{Corresponding author}

Correspondence to Dr Shweta Singh, Additional Professor, Department of Psychiatry, King Georges Medical University, Lucknow. INDIA, email shwetabhanu3gmail.com

\section{Ethics declarations}

\section{Ethics approval and consent to participate}

This study was part of an institutional project on mental health aspects during the pandemic. The proforma contained an assent form for adolescents and a consent form for adults, approved by the institute ethics committee. The ethical approval for conducting the study was obtained from the institutional ethics

Page $16 / 20$ 


\section{Consent for publication}

Not applicable.

\section{Competing interests}

The authors declare that they have no competing interests.

\section{References}

1. COVID-19. Mental IIIness, a "Parallel Pandemic" | UN in Western Europe. In: United Nations Western Europe. https://unric.org/en/covid-19-mental-illness-aparallel-pandemic/. Accessed 27 Mar 2021.

2. Khan AR, Ratele K, Arendse N. Men, Suicide, and Covid-19: Critical Masculinity Analyses and Interventions. Postdigit Sci Educ. 2020;2:651-6. https://doi.org/10.1007/s42438-020-00152-1.

3. Mazumder A, Bandhu Kalanidhi K, Sarkar S, et al. Psycho-social and behavioural impact of COVID 19 on young adults: Qualitative research comprising focused group discussion and in-depth interviews. Diabetes Metab Syndr. 2021;15:309-12. https://doi.org/10.1016/j.dsx.2020.12.039.

4. Barber SJ, Kim H. COVID-19 Worries and Behavior Changes in Older and Younger Men and Women. J Gerontol B Psychol Sci Soc Sci. 2020. https://doi.org/10.1093/geronb/gbaa068.

5. Dong H, Yang F, Lu X, Hao W. Internet Addiction and Related Psychological Factors Among Children and Adolescents in China During the Coronavirus Disease 2019 (COVID-19) Epidemic. Front Psychiatry. 2020;11:. https://doi.org/10.3389/fpsyt.2020.00751.

6. Eden AL, Johnson BK, Reinecke L, Grady SM. Media for Coping During COVID-19 Social Distancing: Stress, Anxiety, and Psychological Well-Being. Front Psychol. 2020;11:. https://doi.org/10.3389/fpsyg.2020.577639.

7. Rodríguez-Hidalgo AJ, Pantaleón Y, Dios I, Falla D. Fear of COVID-19, Stress, and Anxiety in University Undergraduate Students: A Predictive Model for Depression. Front Psychol. 2020;11:591797. https://doi.org/10.3389/fpsyg.2020.591797.

8. Deng J, Zhou F, Hou W, et al. The prevalence of depressive symptoms, anxiety symptoms and sleep disturbance in higher education students during the COVID-19 pandemic: A systematic review and meta-analysis. Psychiatry Res. 2021;113863. https://doi.org/10.1016/j.psychres.2021.113863.

9. Pedrozo-Pupo JC, Pedrozo-Cortés MJ, Campo-Arias A. Perceived stress associated with COVID-19 epidemic in Colombia: an online survey. Cad Saude Publica. 2020;36:e00090520. https://doi.org/10.1590/0102-311x00090520.

10. Mazza MG, De Lorenzo R, Conte C,. Brain. et al. Anxiety and depression in COVID-19 survivors: Role of inflammatory and clinical predictors. Behavior Immunity. 2020;89:594-600. https://doi.org/10.1016/j.bbi.2020.07.037.

11. Özdin S, Bayrak Özdin Ş. Levels and predictors of anxiety, depression and health anxiety during COVID-19 pandemic in Turkish society: The importance of gender. Int J Soc Psychiatry. 2020;66:504-11. https://doi.org/10.1177/0020764020927051.

12. Taylor MR, Agho KE, Stevens GJ, Raphael B. Factors influencing psychological distress during a disease epidemic: data from Australia's first outbreak of equine influenza. BMC Public Health. 2008;8:347. https://doi.org/10.1186/1471-2458-8-347.

13. Qiu J, Shen B, Zhao M, et al. A nationwide survey of psychological distress among Chinese people in the COVID-19 epidemic: implications and policy recommendations. Gen Psych. 2020;33:e100213. https://doi.org/10.1136/gpsych-2020-100213.

14. Online Assessment Measures. https://www.psychiatry.org/psychiatrists/practice/dsm/educational-resources/assessment-measures. Accessed 3 Jun 2021.

15. Narrow WE, Clarke DE, Kuramoto SJ, et al. DSM-5 Field Trials in the United States and Canada, Part III: Development and Reliability Testing of a CrossCutting Symptom Assessment for DSM-5. AJP. 2013;170:71-82. https://doi.org/10.1176/appi.ajp.2012.12071000.

16. Bravo A, Villarosa-Hurlocker M, Pearson M. undefined. College student mental health: An evaluation of the DSM-5 self-rated Level 1 cross-cutting symptom measure. Psychol Assess. 2018;30:1382-9. https://doi.org/10.1037/pas0000628.

17. Cohen S, Janicki-Deverts D, Miller GE. Psychological stress and disease. JAMA: Journal of the American Medical Association. 2007;298:1685-7. https://doi.org/10.1001/jama.298.14.1685.

18. Baik SH, Fox RS, Mills SD, et al. Reliability and validity of the Perceived Stress Scale-10 in Hispanic Americans with English or Spanish language preference. J Health Psychol. 2019;24:628-39. https://doi.org/10.1177/1359105316684938.

19. Lee E-H. Review of the Psychometric Evidence of the Perceived Stress Scale. Asian Nursing Research. 2021;6:121-7. https://doi.org/10.1016/j.anr.2012.08.004.

20. Carver CS. You want to measure coping but your protocol' too long: Consider the brief cope. Int J Behav Med. 1997;4:92. https://doi.org/10.1207/s15327558ijbm0401_6.

21. García FE, Barraza-Peña CG, Wlodarczyk A, et al. Psychometric properties of the Brief-COPE for the evaluation of coping strategies in the Chilean population. Psicologia: Reflexão e Crítica. 2018;31:22. https://doi.org/10.1186/s41155-018-0102-3.

22. Killgore WDS, Cloonan SA, Taylor EC, et al. Suicidal ideation during the COVID-19 pandemic: The role of insomnia. Psychiatry Res. 2020;290:113134. https://doi.org/10.1016/j.psychres.2020.113134. 
23. Kar SK, Sharma E, Agarwal V, et al. Prevalence and pattern of mental illnesses in Uttar Pradesh, India: Findings from the National Mental Health Survey 2015-16. Asian Journal of Psychiatry. 2018;38:45-52. https://doi.org/10.1016/j.ajp.2018.10.023.

24. Gautham MS, Gururaj G, Varghese M, et al. The National Mental Health Survey of India (2016): Prevalence, socio-demographic correlates and treatment gap of mental morbidity. Int J Soc Psychiatry. 2020;66:361-372. https://doi.org/10.1177/0020764020907941.

25. Grover S, Raju VV, Sharma A, Shah R. Depression in Children and Adolescents: A Review of Indian studies. Indian Journal of Psychological Medicine. 2019;41:216-27. https://doi.org/10.4103/IJPSYM.IJPSYM_5_19.

26. Sagar R, Dandona R, Gururaj G, et al. The burden of mental disorders across the states of India: the Global Burden of Disease Study 1990-2017. The Lancet Psychiatry. 2020;7:148-61. https://doi.org/10.1016/S2215-0366(19)30475-4.

27. Cancello R, Soranna D, Zambra G, et al. Determinants of the Lifestyle Changes during COVID-19 Pandemic in the Residents of Northern Italy. International Journal of Environmental Research Public Health. 2020;17:6287. https://doi.org/10.3390/ijerph17176287.

28. Magson NR, Freeman JYA, Rapee RM, et al. Risk and Protective Factors for Prospective Changes in Adolescent Mental Health during the COVID-19 Pandemic. J Youth Adolescence. 2021;50:44-57. https://doi.org/10.1007/s10964-020-01332-9.

29. Guessoum SB, Lachal J, Radjack R, et al. Adolescent psychiatric disorders during the COVID-19 pandemic and lockdown. Psychiatry Res. 2021;291:113264. https://doi.org/10.1016/j.psychres.2020.113264.

30. Becker SP, Dvorsky MR, Breaux R, et al. Prospective examination of adolescent sleep patterns and behaviors before and during COVID-19. Sleep. 2021. https://doi.org/10.1093/sleep/zsab054.

31. Gonzales NA, Tein J-Y, Sandler IN, Friedman RJ. On the Limits of Coping: Interaction between Stress and Coping for Inner-City Adolescents. J Adolesc Res. 2001;16:372-95. https://doi.org/10.1177/0743558401164005.

32. Liu S, Liu Y, Liu Y. Somatic symptoms and concern regarding COVID-19 among Chinese college and primary school students: A cross-sectional survey. Psychiatry Res. 2020;289:113070. https://doi.org/10.1016/j.psychres.2020.113070.

33. Albion M, Fernie K, Burton L. Individual differences in age and self-efficacy in the unemployed. Australian Journal of Psychology. 2005;57:11-9. https://doi.org/10.1080/00049530412331283417.

34. Dumas TM, Ellis W, Litt DM. What Does Adolescent Substance Use Look Like During the COVID-19 Pandemic? Examining Changes in Frequency, Social Contexts, and Pandemic-Related Predictors. J Adolesc Health. 2020;67:354-61. https://doi.org/10.1016/j.jadohealth.2020.06.018.

35. Sun Y, Li Y, Bao Y, et al. Brief Report: Increased Addictive Internet and Substance Use Behavior During the COVID-19 Pandemic in China. Am J Addict. 2020. https://doi.org/10.1111/ajad.13066.

36. Williams DR "The Health of Men: Structured Inequalities and Opportunities". 2008.

37. Lash SJ, Copenhaver MM, Eisler RM. Masculine Gender Role Stress and Substance Abuse Among Substance Dependent Males. Journal of Gender Culture Health. 1998;3:183-91. https://doi.org/10.1023/A:1023293206690.

38. Liu W, Iwamoto D. Conformity to masculine norms, Asian values, coping strategies, peer group influences and substance use among Asian American men. Psychology of Men Masculinity. 2007;8:25-39. https://doi.org/10.1037/1524-9220.8.1.25.

39. Reddy V. MENTAL HEALTH ISSUES AND CHALLENGES IN INDIA: A REVIEW. 2019;7.

40. Bovier PA, Chamot E, Perneger TV. Perceived stress, internal resources, and social support as determinants of mental health among young adults. Qual Life Res. 2004;13:161-70. https://doi.org/10.1023/B:QURE.0000015288.43768.e4.

41. Frone M. Are Work Stressors Related to Employee Substance Use? The Importance of Temporal Context in Assessments of Alcohol and Illicit Drug Use. J Appl Psychol. 2008;93:199-206. https://doi.org/10.1037/0021-9010.93.1.199.

42. Stroebe M, Boelen PA, Hout M, et al. Ruminative coping as avoidance. Eur Arch Psychiatry Clin NeuroSci. 2008;257:462-72. https://doi.org/10.1007/s00406-007-0746-y.

43. Edwards MJ, Holden RR. Coping, meaning in life, and suicidal manifestations: Examining gender differences. J Clin Psychol. 2001;57:1517-34. https://doi.org/10.1002/jclp.1114.

44. Aldwin C, Revenson T. Does Coping Help? A Reexamination of the Relation Between Coping and Mental Health. J Personal Soc Psychol. 1987;53:337-48. https://doi.org/10.1037/0022-3514.53.2.337.

45. Shamblaw AL, Rumas RL, Best MW. Coping during the COVID-19 pandemic: Relations with mental health and quality of life. Can Psychol. $2021 ; 62: 92$. https://doi.org/10.1037/cap0000263.

46. Schneiderman N, Ironson G, Siegel SD. STRESS AND HEALTH: Psychological, Behavioral, and Biological Determinants. Annu Rev Clin Psychol. 2005;1:607-28. doi:10.1146/annurev.clinpsy.1.102803.144141.

47. Rinn W, Desai N, Rosenblatt H, Gastfriend DR. Addiction Denial and Cognitive Dysfunction: A Preliminary Investigation. J Neuropsychiatry Clin Neurosci. Published online 2002:6.

48. Abramson LY, Sackheim HA. A paradox in depression: Uncontrollability and self-blame. Psychol Bull. 1977;84(5):838-51. doi:10.1037/00332909.84.5.838.

49. Tuncay T, Musabak I, Gok DE, Kutlu M. The relationship between anxiety, coping strategies and characteristics of patients with diabetes. Health Quality of Life Outcomes. 2008;6(1):79. doi:10.1186/1477-7525-6-79.

50. Horwitz AG, Hill RM, King CA. Specific Coping Behaviors in Relation to Adolescent Depression and Suicidal Ideation. J Adolesc. 2011;34(5):1077-85. doi:10.1016/j.adolescence.2010.10.004. 
51. Holahan CJ, Moos RH, Holahan CK, Brennan PL, Schutte KK. Stress Generation. Avoidance Coping, and Depressive Symptoms: A 10-Year Model. J Consult Clin Psychol. 2005;73(4):658-66. doi:10.1037/0022-006X.73.4.658.

52. Macía P, Barranco M, Gorbeña S, Álvarez-Fuentes E, Iraurgi I. Resilience and coping strategies in relation to mental health outcomes in people with cancer. PLOS ONE. 2021;16(5):e0252075. doi:10.1371/journal.pone.0252075.

53. Yıldırım M, Kızılgeçit M, Seçer İ, et al. Meaning in Life, Religious Coping, and Loneliness During the Coronavirus Health Crisis in Turkey. J Relig Health. 2021;60(4):2371-85. doi:10.1007/s10943-020-01173-7.

\section{Figures}

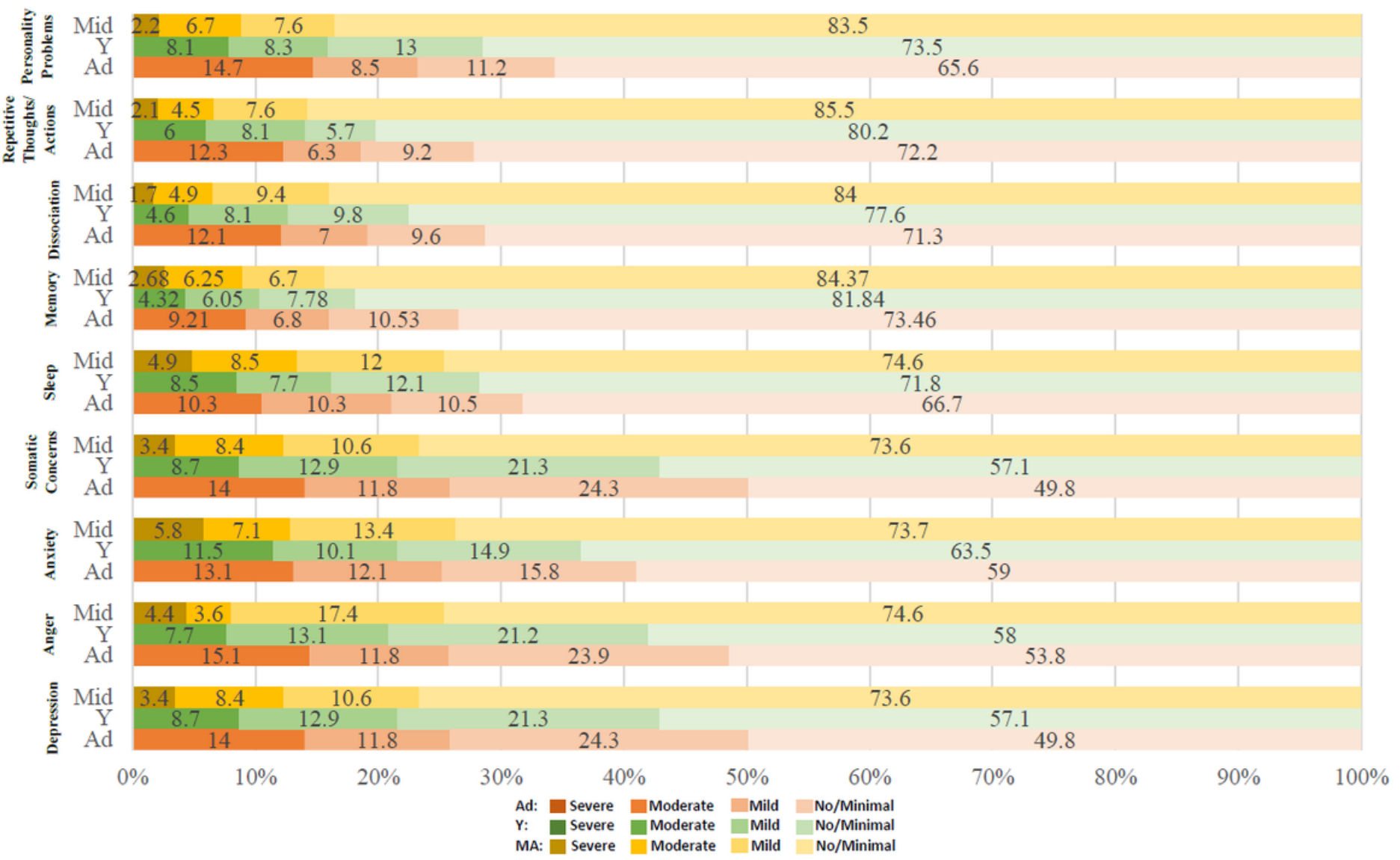

\section{Figure 1}

Severity of Mental Health Symptoms across Age groups 


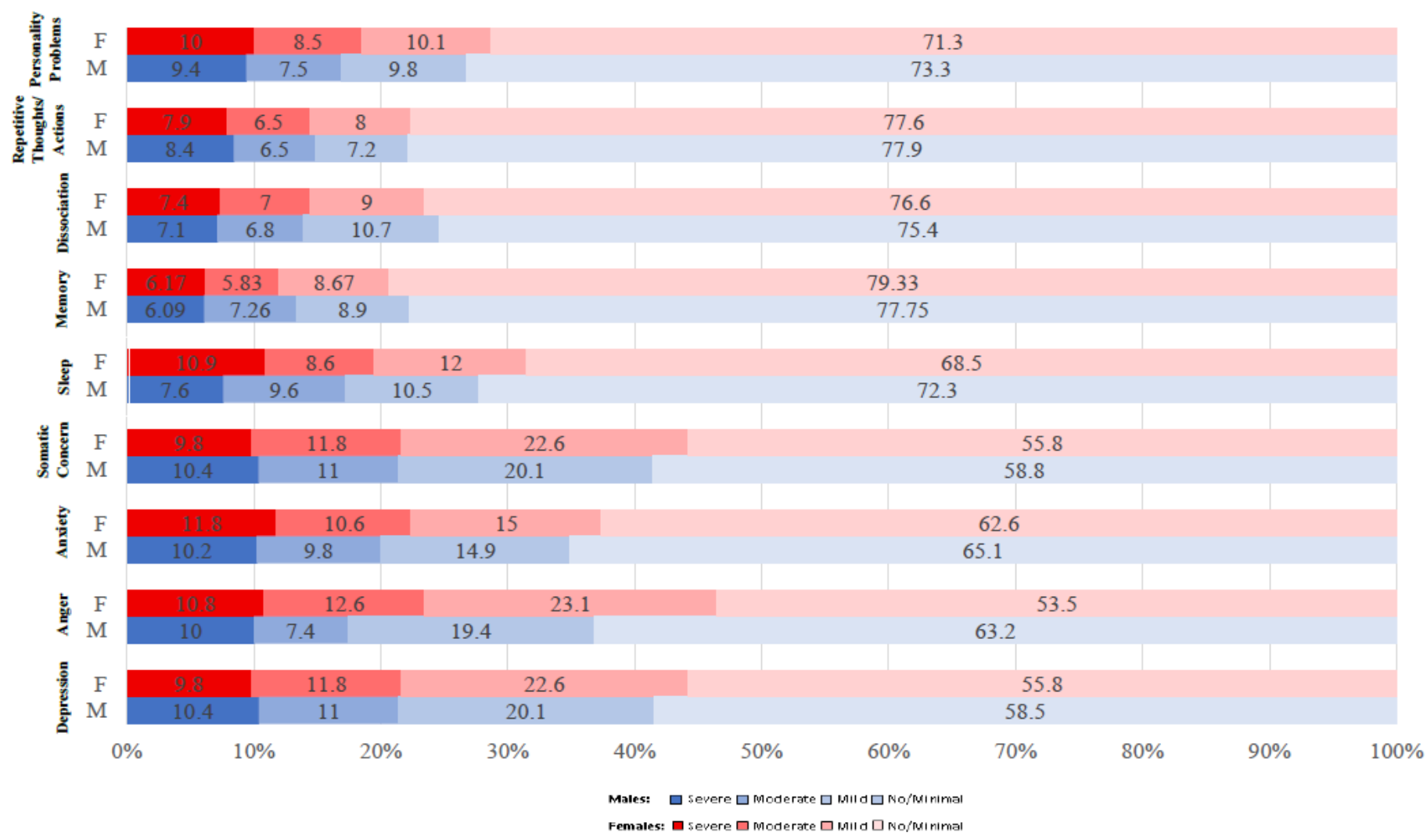

\section{Figure 2}

Severity of Mental Health Symptoms across gender groups

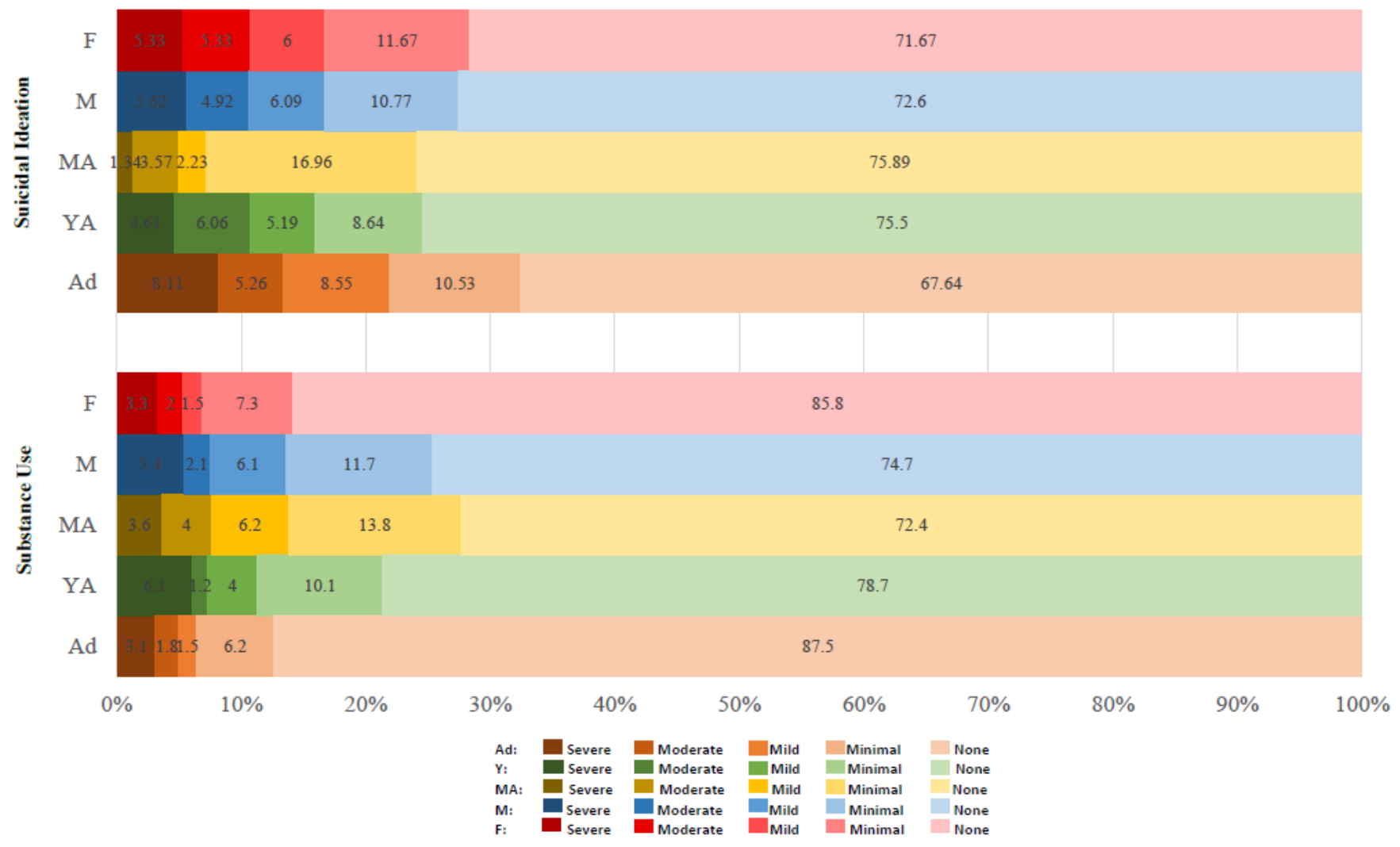

\section{Figure 3}

Severity of Symptoms for Substance Use and Suicidal Ideation - Age \& Gender Comparison

Page 20/20 